Journal of Engineering and Applied Sciences 15 (7): 1645-1651, 2020

ISSN: 1816-949X

(C) Medwell Journals, 2020

\title{
Novel Bio-Filter Forsolar Spectral Selection in Photovoltaic Cells
}

\author{
${ }^{1,2}$ E. Emetere Moses, ${ }^{1}$ Gabe-Oji Testimony, ${ }^{1}$ M.L. Akinyemi and ${ }^{1}$ W.A. Ayara \\ ${ }^{1}$ Department of Physics, Covenant University Canaan land, P.M.B 1023, Ota, Nigeria \\ ${ }^{2}$ Department of Mechanical Engineering Science, University of Johannesburg, \\ Johannesburg, South Africa
}

\begin{abstract}
The solar spectrum of light incident on the solar cell would affect its output per time. It is reported that some geographical locations are exposed to harsh solar radiation that has resulted to reduced lifespan and performance of Photovoltaic (PV) panels. In this research, the spectral filtering was first carried-out in the dark room and then a bio-filter material was synthesized to serve as filter in a live experiment. The bio-optical material was copper coated ixora-methanol extract. The results reveal that the biofilter were effective and had the potential to stabilize the measured parameter. Further research was recommended.
\end{abstract}

Key words: Solar energy, solar, spectral filtering, photovoltaic cells, recommended

\section{INTRODUCTION}

The sun radiates waves within three major regions of the electromagnetic spectra, i.e., infrared spectrum, ultra violet spectrum and visible light spectrum. The infrared spectrum refers to the invisible part of the electromagnetic spectrum with wavelengths longer than those of visible light but less than that of microwaves, wavelengths of infrared ranges from about 700-1 mm. Hence, the energy of infrared is less than that of visible light. This wave spectrum is commonly associated with heat radiated by bodies. The visible light spectrum is the part of the electromagnetic spectrum that the human eye can detect. Its wavelength ranges from 380-750 nm. Ultraviolet spectrum has wavelengths shorter than that of visible light but longer than that of X-rays (between 10-400 nm). Hence, ultraviolet has more energy and higher frequency than visible light. Ultraviolet radiation from the sun is harmful to human beings due to its high energy and leads to skin cancer. The ozone layer in the atmosphere protects the Earth from these harmful rays.

Solar radiation in the West African climate system is very peculiar has it has been spotted as the main cause of lower life span and efficiency of Photovoltaic (PV) panels in the region (Emetere et al., 2016). It is generally observed that the performance of the PV panel reduce with time thereby increasing the maintenance cost of generating solar energy. A typical example is the reduced solar grid power generation in South Africa (Michael et al., 2019; Emetere and Akinyemi, 2017). This challenge establishes that there is harsh solar radiation in some geographical location of the Earth. Hence, there is the need to incorporate spectra filtering into the mechanism of PV panel.
Spectral filtering involves the removal of spectral power at some chosen frequencies and wavelengths while retaining other frequencies and wavelengths (Hazan et al., 2018). This filtering is achieved by allowing the light pass through a plastic or glass aperture that has been specially, treated to transmit or absorb and reflect some wavelengths and frequencies (Eweda and Macchi, 1987; Shynk and Gooch, 1985). Spectral filters operate as either band pass or band stop. Band pass permits frequencies within a certain range and rejects (attenuates) frequencies outside a certain range while band-stop filter or band-rejection filter permits most frequencies but refuse those in a specific range to very low levels (Buckley, 1987).

In this research, Ixora coccinea linn. (Rubiaceae) extract was used as the bio-optical filter. Ixora is known in different regions of the Earth with many names such as: Jungle of Geranium, West Indian Jasmine, Ponna, Flame of the woods, Vetchi in Ayurveda, Rangan, Kheme, etc.

Ixora coccinea linn. is flowering plant that belongs to the Rubiaceae family. This plant is common in Africa, Southern Asia and some parts of India. The Ixora plant possesses high medicinal value (Dontha et al., 2015). The Ixora plant is one of the most research plants (Nayak et al., 1999; Darwish and Ibraheim, 2003 Maniyar and Bhixavatimath, 2011).

\section{MATERIALS AND METHODS}

The spectra selection was first carried in the dark room using: the $3 \mathrm{~W}$ Mono Crystalline solar panels, $4 \mathrm{~W}$ Polycrystalline solar panels, $2 \mathrm{~mm}$ connecting wires, data logger, digital multimeter, retort stand, solarimeter, halogen lamp, colour filters and liquid solid filter. The rating of the monocrystalline solar panel is: nominal peak 


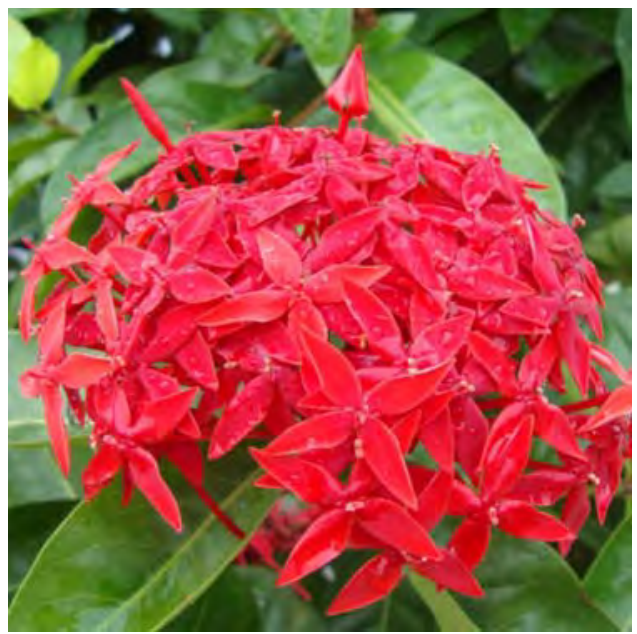

Fig. 1: Ixora coccinea linn. (Rubiaceae)

power $(+-3 \%)($ pmax $)=3 \mathrm{~W}$, open circuit voltage $($ voc $)=10.8 \mathrm{~V}$, short circuit current (isc) $=418$ $\mathrm{mA}$; maximum power voltage $(\mathrm{vmp})=8.2 \mathrm{v}$; maximum power current (imp) $=366 \mathrm{~mA}$ and standard test conditions $=1000 \mathrm{WM}^{2} .25 \mathrm{c}$ AM 1.5. The rating of the polycrystalline solar panel is: nominal peak power $(+-3 \%)($ pmax $)=4 \mathrm{~W}$; open circuit Voltage $($ Voc $)=22.466 \mathrm{~V}$; short circuit current $(\mathrm{Isc})=0.235 \mathrm{~A}$; maximum power Voltage $(\mathrm{Vmp})=18.436 \mathrm{~V}$; maximum power current $(\mathrm{Imp})=0.220 \mathrm{~A}$, standard test conditions $=1000 \mathrm{~W} / \mathrm{m}^{2} 250 \mathrm{C}$ AM 1.5 .

The panels were connected in series. The angular positioning of the panels to the light source was enabled by the retort stand. The solarimeter was used to measure the amount of radiation produced by the halogen lamp and the different colour filters were used to do the spectra filtering of light incidental on the solar panel. The angle of inclination of the panel to the light source was varied.

The Ixora coccinea linn. flower was blended with methanol and filtered. The filtrate collected into a beaker. The $10 \mathrm{~mL}$ of the filtrate was mixed with 0.0045 mole of $\mathrm{Cu}\left(\mathrm{NO}_{3}\right)_{2} \cdot 3 \mathrm{H}_{2} \mathrm{O}$ and left a day to enable proper dissolution of copper. Ixora coccinea flower is of ursolic acid chemotype (Elumalai et al., 2012) that is structurally presented in Fig. 1 and 2.

The data logger can accommodate six panels but four panels were used in total (two monocrystalline and two polycrystalline). One monocrystalline and polycrystallinepanel was unsprayed and the other two panels (monocrystalline and polycrystalline) were sprayed. The unsprayed panels were used as control mechanism to monitor the sprayed panels.

Before the panels were sprayed, it was cleaned with distilled water. The panels were afterwards put under the sun and the readings from the panels were recorded on the logger and stored in an SD card.

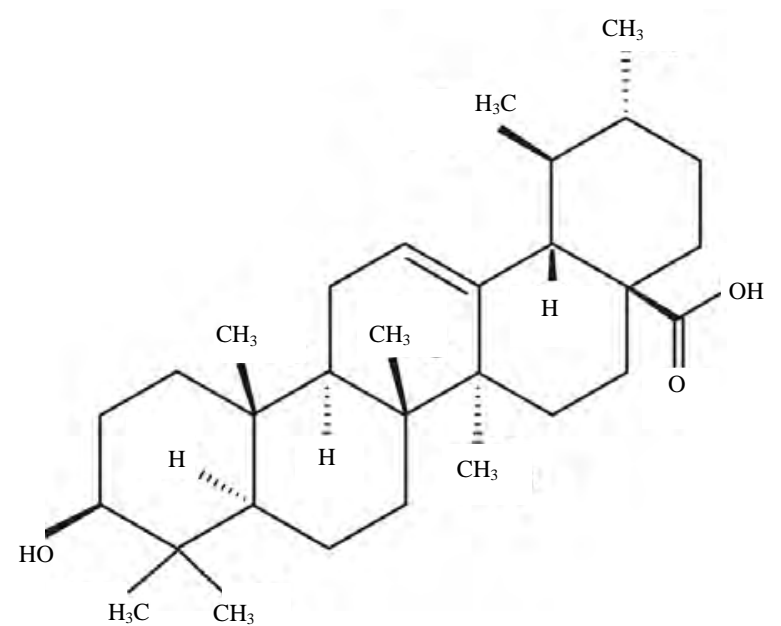

Fig. 2: Ursolic acid in Ixora coccinea linn.

\section{RESULTS AND DISCUSSION}

The analysis of the results obtained from the monocrystaline and polycrystalline PV panel is presented in Fig. 3-12. The laboratory filtering results using filters is presented in Fig. 3. It was observed that the radiation of the white light is attenuated when each colour filter is used. Yellow and orange filters gave the least attenuation with the highest magnitude of power. The blue filter had the highest attenuation and the least power as shown in the graph. After the laboratory experiment, the extracted was sprayed on the solar panels as already described in the previous section.

Figure 4 below represents radiation against time, the radiation rises and then becomes stable after undergoing a transient state. Rapid fluctuation were observed at higher and lower values of radiation. Thick lines represent rapid fluctuations in radiation within the given time interval. Figure 5 below shows the temperature distribution over the sprayed monocrystalline panel. It is observed that there were step-wise decreases as presented in Fig. 5. When compared to the UV radiation in Fig. 4, it can be inferred that bio-filter was able to control the temperature distribution over the surface of the PV panel.

Figure 6 presents the current of the unsprayed panel (current 1) and current of the sprayed panel(current 2) against time. Current of the unsprayed panel is higher than current of the sprayed panel. However, it was observed that both sprayed and unsprayed panel show a region of rapid fluctuations towards lower values of current. However, the low current is attributed to the solarirradiance at the time the measurement was taken.

Figure 7 presents the graph of voltage against time for both sprayed and unsprayed monocrystalline panels. It is 

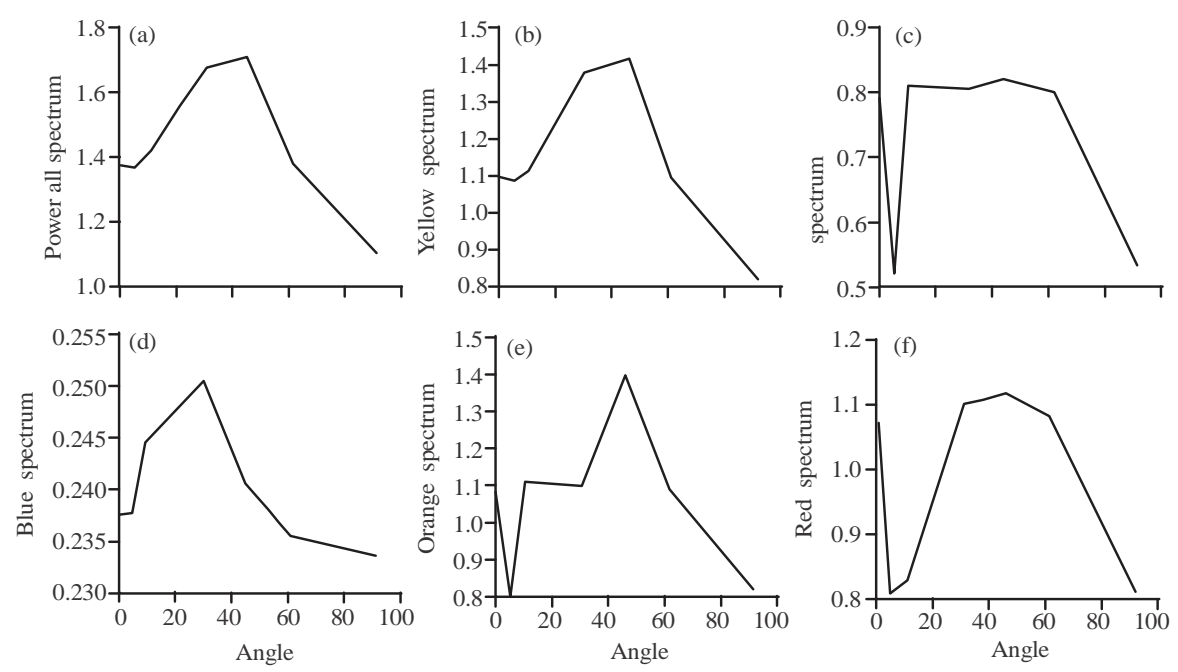

Fig. 3 (a-f): Comparison of power against angle for different spectrum of visible light, (a) Power vs. angle $\mathrm{Gw}=255$, (b) Power vs. angle $G y=227$, (c) Power vs. angle $G g=160$, (d) Power vs. angle Gb = nill, (e) Power vs. angle $\mathrm{Go}=209$ and $\mathrm{f}$ Power vs. angle $\mathrm{Gr}=194$

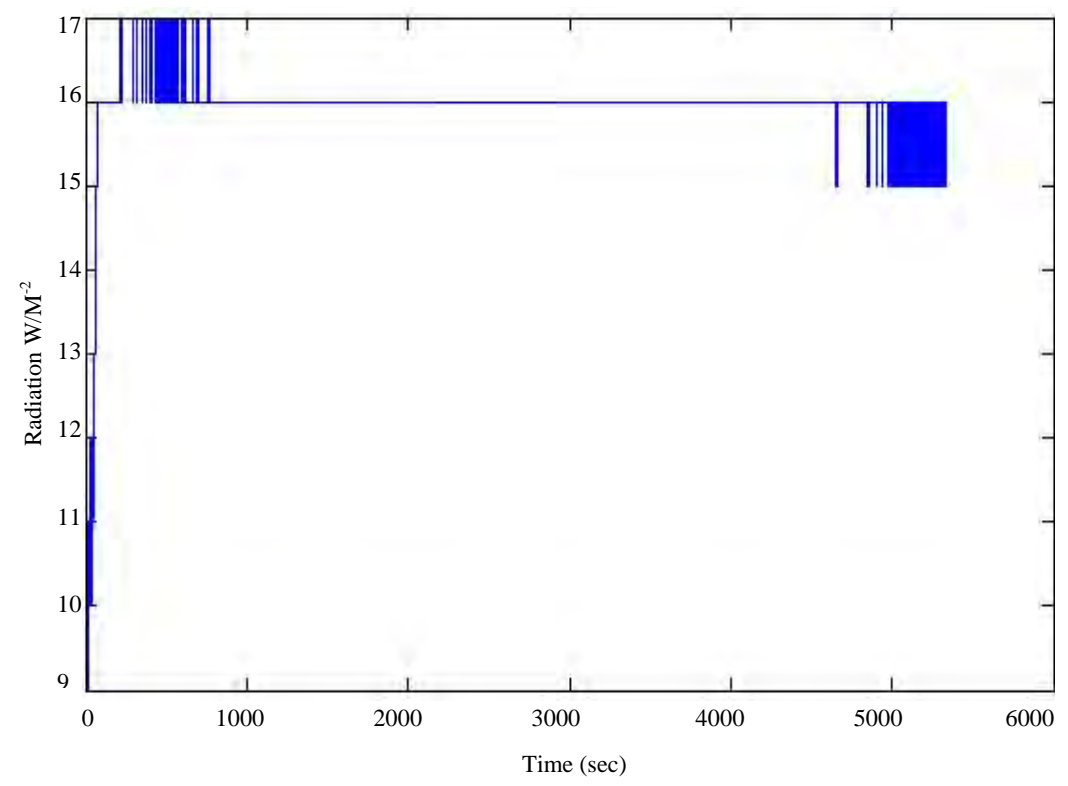

Fig. 4: Radiation signatures of sprayed monocrystalline panel

observed that the voltage in the unsprayed panel is higher than that of the sprayed panel (voltage 2). However, both panels show rapid fluctuations and a very slow stepwise decrease. A close observation of Fig. 7 shows that bio-filter was able, i.e., to an extent-stabilize the voltage output of the PV panel.

Figure 8 presents the graph of power output versus time. Like the voltage output, the power output of the unsprayed panel (power 1) is higher than the sprayed panel (power 2). Both of them show rapid fluctuations and a slow stepwise decrease. Like in Fig. 7, the biofilter was able, i.e., to an extent-stabilize the power output of the PV panel.

Figure 9 shows a slightly increasing fluctuating radiation with time in the sprayed polycrystalline panel. The radiation increase is stepwise with a spike in radiation that makes it different from the monocrystalline radiation measurement in Fig. 4.

Figure 10 below shows the graph of temperature against time on the sprayed polycrystalline panel. It is 


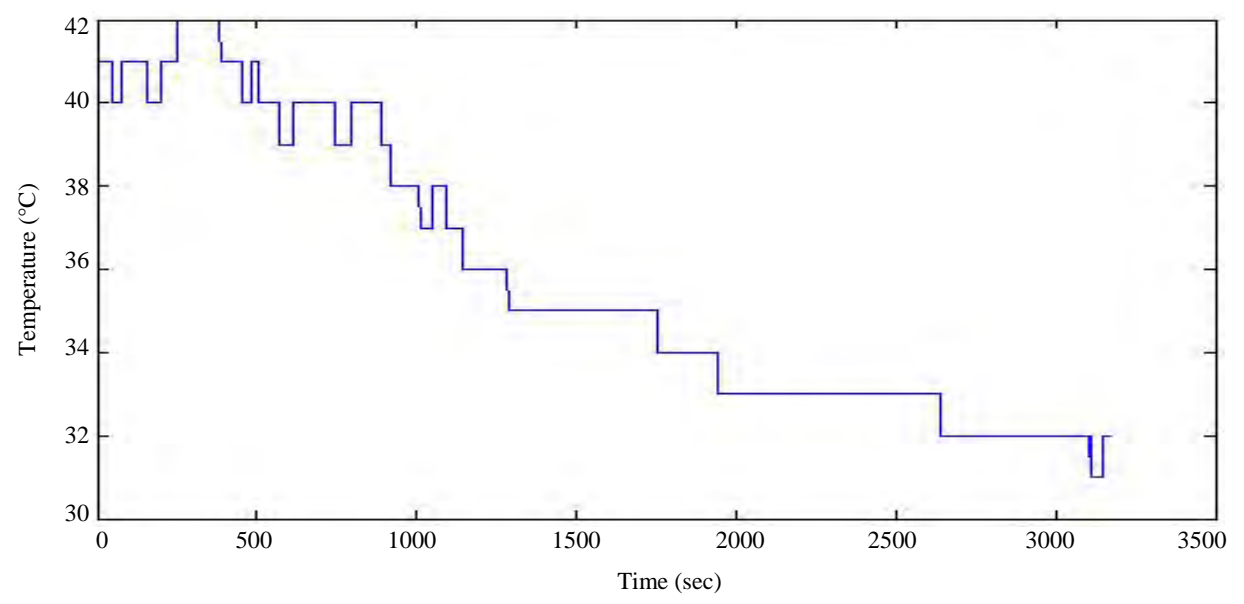

Fig. 5: Temperature distribution of sprayed monocrystalline panel

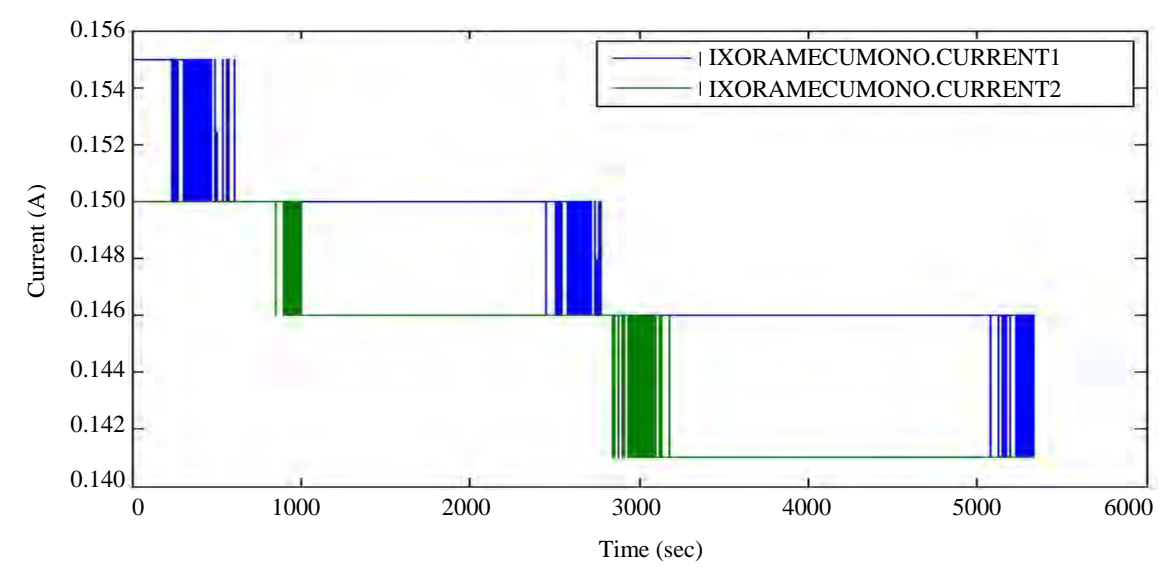

Fig. 6: Current vs. time of sprayedand unsprayed monocrystalline panel

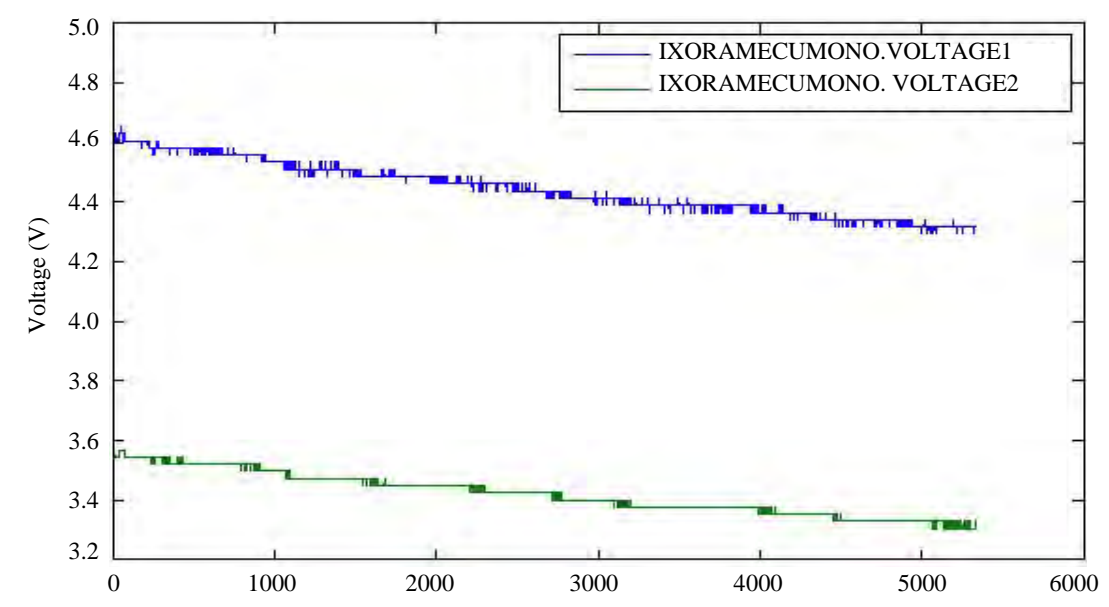

Fig. 7: Voltage vs time of sprayedand unsprayed monocrystalline panel

observed that the temperature increases while the temperature on monocrystalline panel decreases.
Figure 11 below shows the current against time of the unsprayed panel (current 1) and sprayed panel. It is 
J. Eng. Applied Sci., 15 (7): 1645-1651, 2020

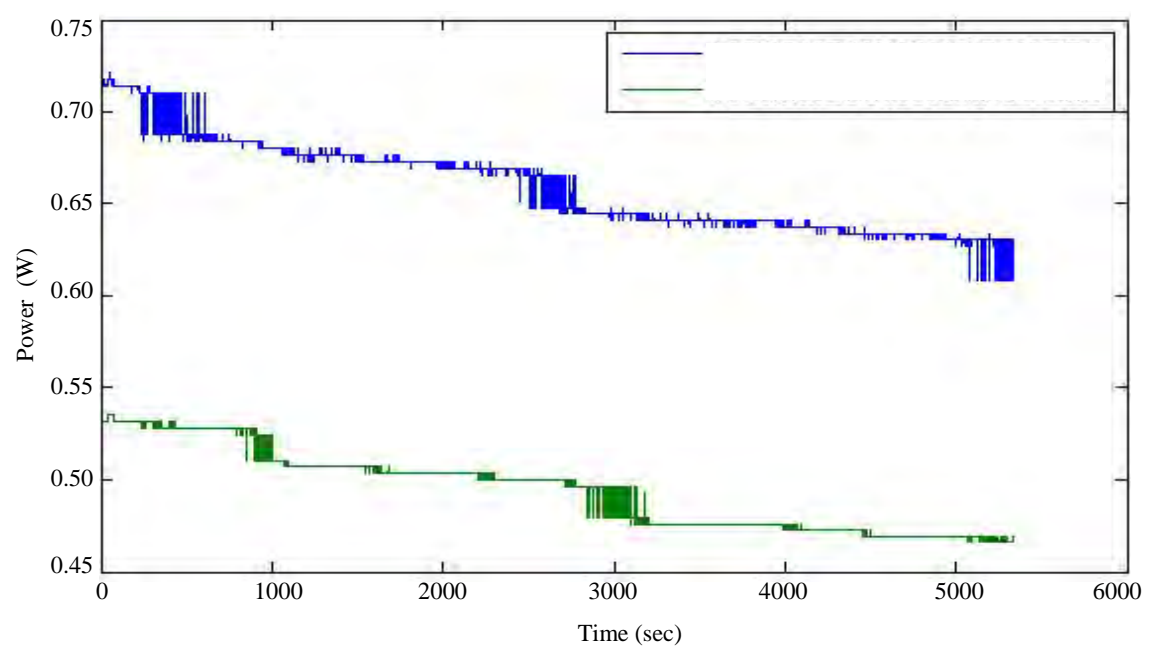

Fig. 8: Power vs time of sprayedand unsprayed monocrystalline panel

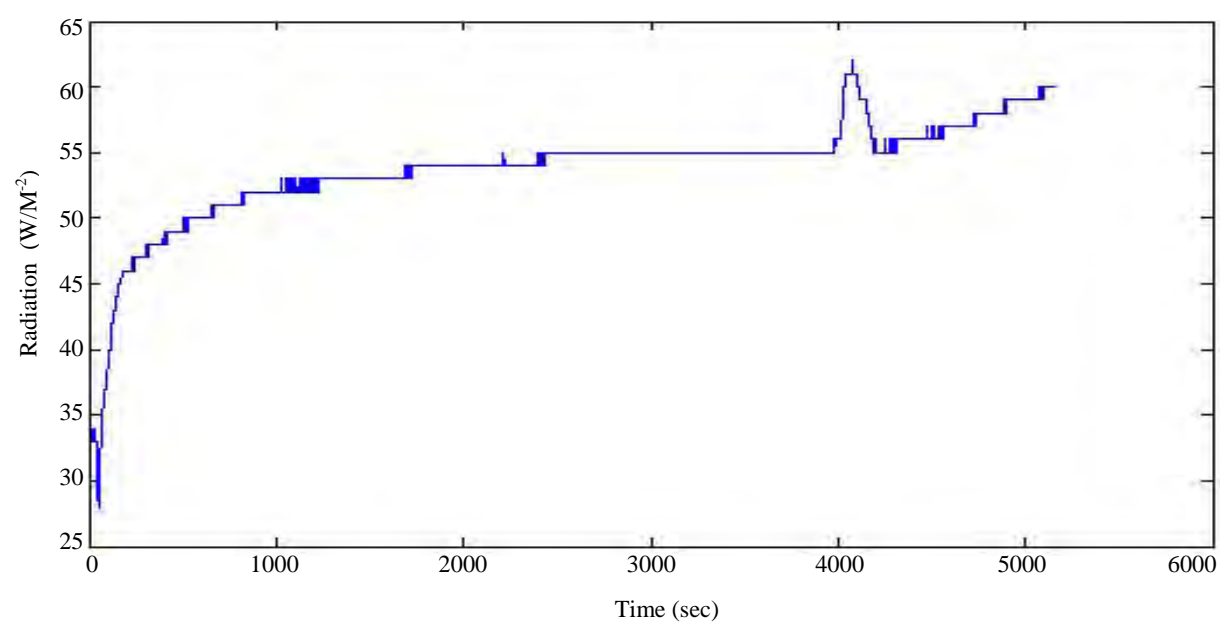

Fig. 9: Radiation signature in sprayed polycrystalline panel

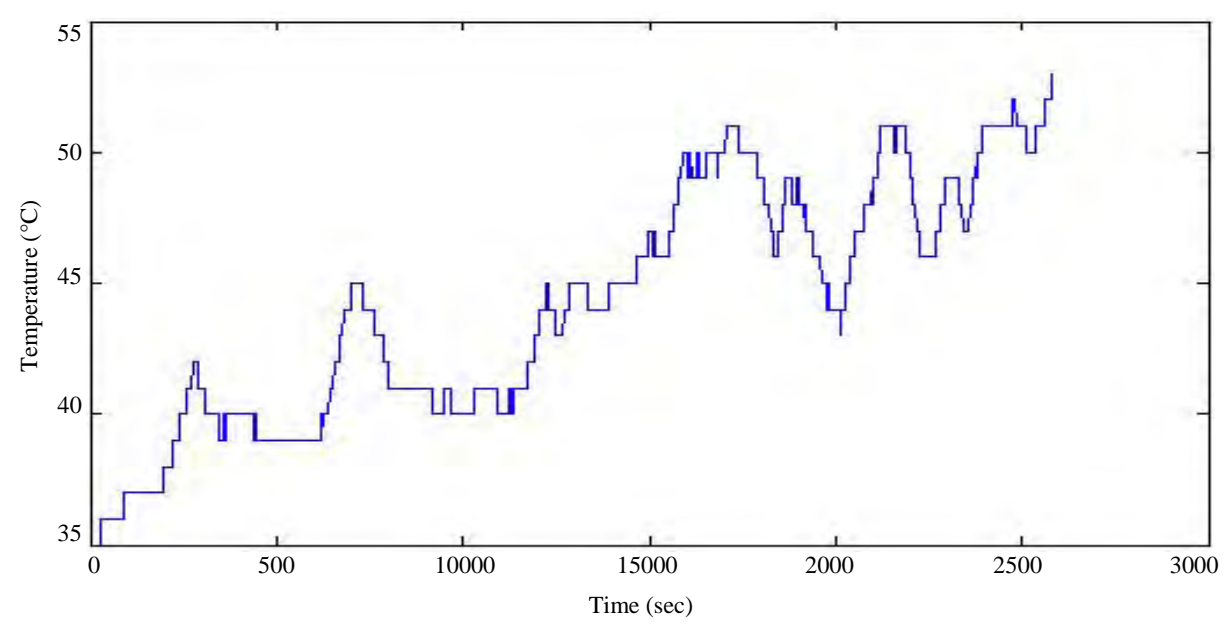

Fig. 10: Temperature distribution of sprayed polycrystalline panel 


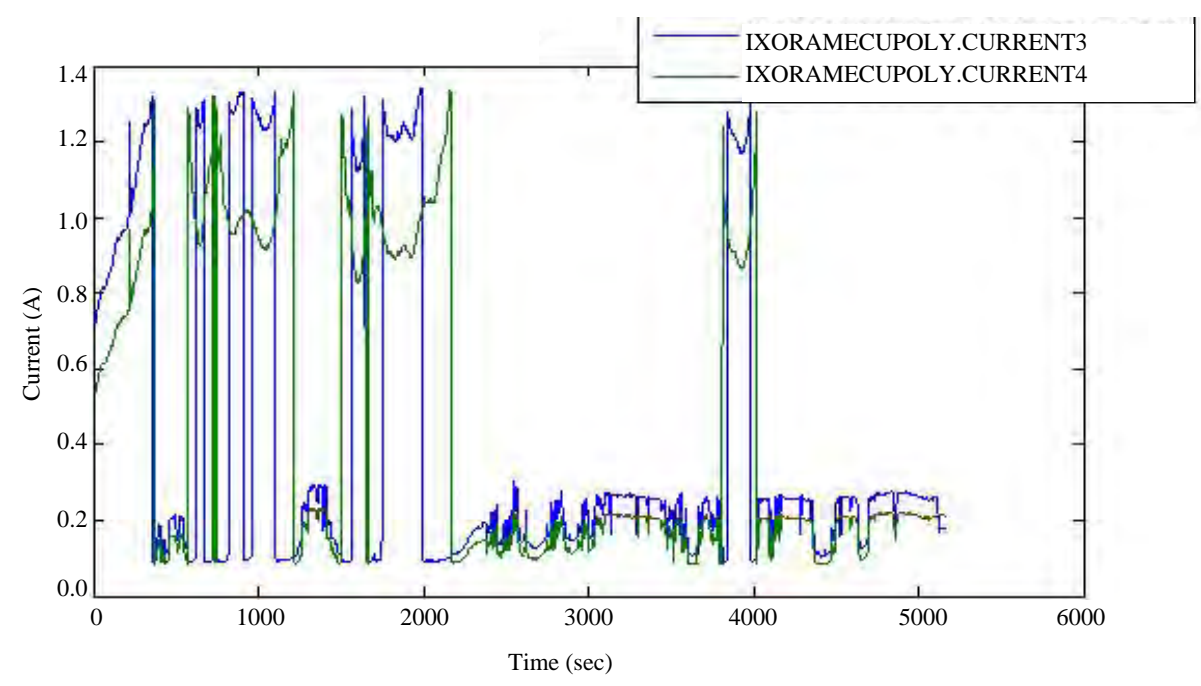

Fig. 11: Current against time of sprayed and unsprayed polycrystalline panels

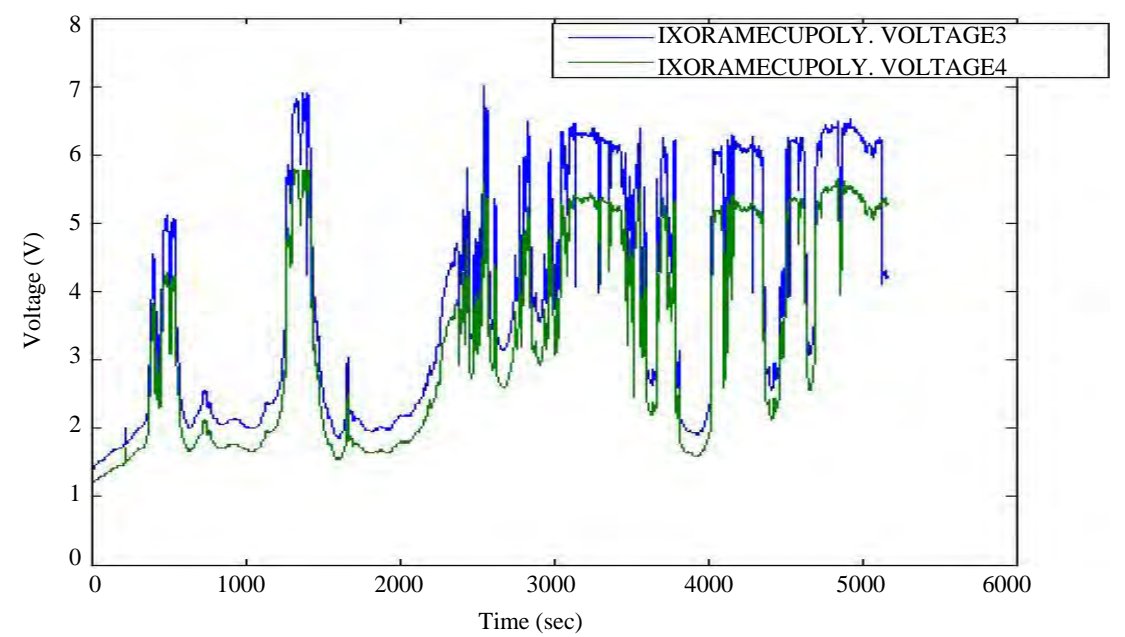

Fig. 12: Voltage against time of sprayed and unsprayed polycrystalline panels

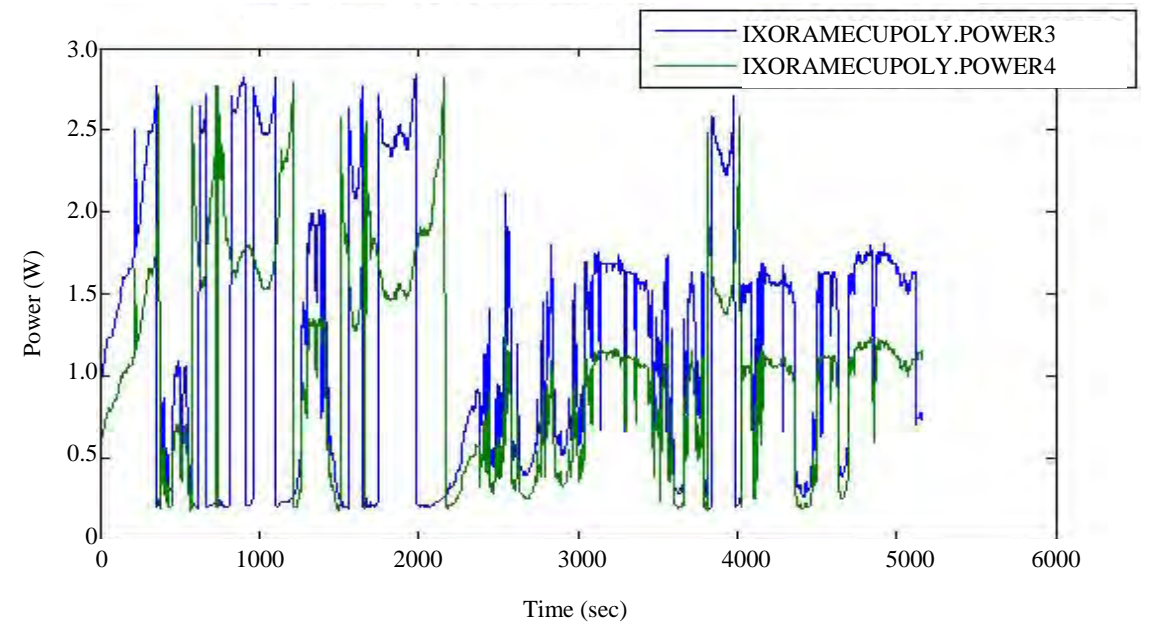

Fig. 13: Power against time of sprayed and unsprayed polycrystalline panels 
observed that the current in the unsprayed panel was was almost the same as the sprayed panel. In this regard, it was observed that the bio-filter was able to fairly stabilize the current output in the sprayed panel.

Figure 12 presents the voltage against time of the sprayed and unsprayed panel. It was observed that the voltage output in the sprayed panel is lower than that of the unsprayed panel. Thick lines represent rapid fluctuations in the voltage. However, the thick lines were not noticed in the sprayed panel because of the stabilizing ability of the bio-filter.

Figure 13 presents the power generation of the unsprayed and sprayed panel. The unsprayed panel (power 3) had higher power generation than that of the sprayed panel (power 4). Like other parameters mentioned above, the bio-filter was able to stabilize the output from the panel.

\section{CONCLUSION}

Ixora-Methanol copper coated biofilter has been proven to be a good stabilizer of measured parameters. Though it had no effect in increasing the measured parameter in the monocrystalline and polycrystalline panels,the stability of the measured parameter is a clear evidence that the synthesize extract is a viable candidate to cushion the effect of harsh solar radiation effect on the performance and lifespan of PV panels.

\section{REFERENCES}

Buckley, K., 1987. Spatial/spectral filtering with linearly constrained minimum variance beam formers. IEEE. Trans. Acoust. Speech Signal Process., 35: 249-266.

Darwish, F.M. and Z.Z. Ibraheim, 2003. Phytochemical study of Ixora finlaysoniana wall. Ex. g. don growing in Egypt. Bull. Pharm. Sci. Assiut, 26: 91-96.

Dontha, S., H. Kamurthy and B. Mantripragada, 2015. Phytochemical and pharmacological profile of Ixora: A review. Int. J. Pharm. Sci. Res., 7: 567-584.
Elumalai, A., C. Eswaraiah, Y. Venkatesh and C. Narendar, 2012. Phytochemical and pharmacological profile Of Ixora coccinea Linn. Int. J. Pharm. Life Sci., 3: 1563-1567.

Emetere, M. and M.L. Akinyemi, 2017. A review on the effects and defects of electromagnetic field to human. Res. J. Med. Sci., 11: 19-22.

Emetere, M.E., M.L. Akinyemi and E.B. Edeghe, 2016. A simple technique for sustaining solar energy production in active convective coastal regions. Int. J. Photoenergy, 2016: 1-11.

Eweda, E. and O. Macchi, 1987. Convergence of the RLS and LMS adaptive filters. IEEE. Trans. Circuits Syst., 34: 799-803.

Hazan, E., H. Lee, K. Singh, C. Zhang and Y. Zhang, 2018. Spectral Filtering for General Linear Dynamical Systems. In: Advances in Neural Information Processing Systems, Bengio, S., H. Wallach, H. Larochelle, K. Grauman, N. Cesa-Bianchi and R. Garnett (Eds.)., Curran Associates, Inc., USA., pp: 4634-4643.

Maniyar, Y. and P. Bhixavatimath, 2011. Evaluation of the hypoglycaemic and hypolipidaemic activities of the aqueous extract of the leaves of Ixora coccinea Linn in diabetic rats. J. Clin. Diagn. Res., 5: 1381-1384.

Michael, S., A. Beauvais, N. Chevillard and M.G. Paredes et al., 2019. Global market outlook for solar power 2018-2022. Solar Power Europe, https://www.solarpowereurope.org/wp-content/uplo ads/2018/09/Global-Market-Outlook-2018-2022.pdf

Nayak, B.S., A.L. Udupa and S.L. Udupa, 1999. Effect of Ixora coccinea flowers on dead space wound healing in rats. Fitoterapia, 70: 233-236.

Shynk, J.J. and R.P. Gooch, 1985. Frequency-domain adaptive pole-zero filtering. Proc. IEEE., 73: 1526-1528. 